\title{
The Italian version of the Wong-Law Emotional Intelligence Scale (WLEIS-I): A second-order factor analysis
}

\author{
Paolo Iliceto ${ }^{\mathrm{a}}$, Emanuele Fino ${ }^{\mathrm{b}, *}$ \\ a SEP Statistics and Psychometrics Ltd, Rome, Italy \\ ${ }^{\mathrm{b}}$ Academic Unit of Medical Education, University of Sheffield, Beech Hill Road, S10 2RX Sheffield, United Kingdom
}

\section{A R T I C L E I N F O}

\section{Article history:}

Received 8 March 2017

Received in revised form 3 May 2017

Accepted 4 May 2017

Available online 8 May 2017

\section{Keywords:}

Emotional Intelligence

Wong-Law Emotional Intelligence Scale

WLEIS

Personality

Attachment

Italy

\begin{abstract}
A B S T R A C T
The Wong and Law Emotional Intelligence Scale (WLEIS) is a 16-item self-report measure of emotional intelligence, based on the revised model by Mayer and Salovey. The scale measures four dimensions: Self-Emotional Appraisal, Others' Emotion Appraisal, Use Of Emotion, Regulation Of Emotions, loading onto a higher-order emotional intelligence factor. The WLEIS has been translated and validated in several cultural contexts, but to date there is no Italian translation, and no studies investigated its factor structure in the Italian community. This study aimed at translating the WLEIS in Italian, analysing its psychometric properties in Italian adults from the community, and testing the fit between the data and the original model by Wong and Law. We also tested correlations between WLEIS and measures of the Big Five personality factors and attachment. We found that the scale was internally consistent, and the second-order factor solution fit the data well. We also found significant positive correlations with agreeableness, extraversion, and perception of the self and the others, and negative correlation with neuroticism. These results represent a preliminary attempt to study the application of the WLEIS in Italian community settings, with implications for assessment and intervention to enhance the subjective and psychological well-being of individuals.
\end{abstract}

(C) 2017 Elsevier Ltd. All rights reserved.

\section{Introduction}

In the last decades, there has been an increasing corpus of research to understand the emotional foundations of human thinking and behaviour (Barsade, Brief, \& Spataro, 2003), and several studies have focussed on the concept of Emotional Intelligence (EI) (Mayer \& Salovey, 1997).

Emotional Intelligence (EI) has been theorized in terms of "a constellation of traits and self-perceived abilities" (Petrides \& Furnham, 2001, p. 425). There are two major theoretical models of EI, namely (1) Trait EI and (2) Ability EI. Petrides and Furnham (2000, 2001) identified the difference between Trait EI and Ability EI in the measurement approach.

Trait EI is defined as "a constellation of emotional self-perceptions" (Petrides, Pita, \& Kokkinaki, 2007 as cited in Cooper \& Petrides, 2010, p. 449), overlapping with personality traits such as empathy, emotional expression, adaptability, and self-control (Petrides, 2011). Trait EI is concerned with the cross-situational consistency of behaviours, and it can be assessed through self-reports (Petrides \& Furnham, 2000). Ability EI has been originally defined as "the ability to monitor one's own and others' feelings and emotions to discriminate among them and to use this information to guide one's thinking and actions" (Salovey \&

\footnotetext{
* Corresponding author.

E-mail addresses: paolo.iliceto@statpsyc.com (P. Iliceto), e.fino@sheffield.ac.uk (E. Fino).
}

Mayer, 1990, p. 189). Subsequently, Mayer and Salovey (1997) added further specification to such definition, describing EI as the "the ability to perceive and express emotion, assimilate emotion in thought, understand and reason with emotion, and regulate emotion in the self and others" (p. 5). According to Petrides and Furnham (2000), this approach defines EI in terms of an information-processing ability, whereas Ability EI can be assessed through maximum-performance tests. Research showed that measures of ability EI following the model of EI proposed by Mayer and Salovey are significantly linked with dysfunctional attachment styles and relational problems (Bonab \& Koohsar, 2011; Cherry, Fletcher, \& O'Sullivan, 2013; Gunning, Waugh, Robertson, \& Holmes, 2011).

A number of self-report scales have been constructed and validated to assess EI. Among these, the Wong and Law Emotional Intelligence Scale (WLEIS; Wong \& Law, 2002) is considered as theoretically as a sound and internally consistent self-report measure of EI (Carvalho, Guerrero, Chambel, \& González-Rico, 2016; Libbrecht, De Beuckelaer, Lievens, \& Rockstuhl, 2014). Wong and Law (2002) developed the WLEIS on the basis of the revised four-dimensional EI model theorized by Salovey and Mayer (1990) and Mayer and Salovey (1997). In this model, EI represents "a set of interrelated skills" (p. 244), including four specifically abilities, namely: (1) "to perceive accurately, appraise, and express emotion"; (2) "to access and/or generate feelings when they facilitate thought"; (3) "to understand emotion and emotional 
knowledge"; (4) "to regulate emotions to promote emotional and intellectual growth" (Mayer \& Salovey, 1997, p. 10). The scale is composed of 16 items rated on a 7-point Likert-type scale ( $1=$ strongly disagree, 7 = strongly agree), measuring four dimensions of Trait EI: (1) Self-Emotional Appraisal (SEA), i.e. the ability to process complex emotions and to express emotions; (2) Others' Emotion Appraisal (OEA), i.e. the ability to understand and process others' emotions; (3) Use Of Emotion (UOE), i.e. the ability to use emotions and achieve success in personal and working life; (4) Regulation Of Emotions (ROE), i.e. the ability to self-regulate emotions and cope with distress effectively. In their original study, Wong and Law (2002) performed a second-order confirmatory factor analysis, and compared two models: In the first model all the items loaded a single EI dimension, while in the second model the four dimensions with their relevant items loaded a second-order factor. The single-factor model was unsatisfactory, while the second-order model "fitted the data reasonably well", and the authors concluded that the four factors represent "an underlying multidimensional EI construct" (p. 260). Wong and Law (2002) reported that the scale was internally consistent, with values of Cronbach's $\alpha$ ranging from 0.83 to 0.90 both at the total scale and the sub-scale level, and average loadings of the 16 items on their respective dimensions of about 0.80 . A recent study showed that the WLEIS has metric and configural invariance across three groups of Chinese students (Li, Saklofske, Bowden, Fung, \& Yan, 2012).

Some authors identified the WLEIS as a self-report measure of Trait EI (Pérez, Petrides, \& Furnham, 2005), overlapping with personality dimensions (Brannick et al., 2009). In fact, a study comparing the measurement properties of the WLEIS and the Meyer-Salovey-Caruso Emotional Intelligence Test (MSCEIT) showed that WLEIS scores were more highly correlated with personality scales than the MSCEIT scores (Brannick et al., 2009). In terms of discriminant validity, the authors concluded that "measures of the Big Five personality traits may account for nearly $50 \%$ of the variance in overall WLEIS" (p. 167). However, a recent research conducted by LaPalme, Wang, Joseph, Saklofske, and Yan (2016) aimed at assessing measurement equivalence of the WLEIS, showed that the IRT DIF approach suited the WLEIS better than the ideal-point model, which in contrast suits Trait EI measures better. The authors commented that "although the WLEIS is a self-report measure, it purports to measure EI as an ability" (p. 197), suggesting the need for further research on the construct measured by the scale.

Culturally-mediated codification of emotional responses, display rules, and use of emotion-related information require the cross-cultural validation of measure of EI (Austin, Saklofske, \& Egan, 2005). However, research supports the cross-cultural generalizability of the WLEIS. Fukuda, Saklofske, Tamaoka, and Lim (2012) showed that the Korean version of the WLEIS was consistent with the original four-factor model, providing evidence to the internal consistency of the scale in non-Western cultural contexts. Libbrecht et al. (2014) examined invariance of the WLEIS scores across two different countries, namely Singapore $(n=505)$ and Belgium $(n=339)$. The authors found that the measurement structure of the WLEIS was invariant across the two cultural contexts. In the same vein, previous studies found that the WLEIS is an internally consistent scale to assess EI in populations from Barbados (Devonish \& Greenidge, 2010), Canada (Kaushal \& Kwantes, 2006), China (Law, Wong, \& Song, 2004; Wong \& Law, 2002), Greece (Kafetsios \& Zampetakis, 2008), Israel (Zysberg \& Rubanov, 2010), Japan (Fukuda et al., 2011), Korea (Kim, Cable, Kim, \& Wang, 2009), Nigeria (Salami, 2009), Taiwan (Wang \& Huang, 2009), Turkey (Güleryüz, Güney, Aydin, \& Aşan, 2008), United Kingdom (Lindebaum \& Cartwright, 2010), and United States (Joseph \& Newman, 2010; Whitman, Van Rooy, Viswesvaran, \& Kraus, 2009).

A corpus of recent research in the field of EI shows the successful application of measures of EI in the Italian context. D'Amico and Curci (2010) investigated EI in a community sample of Italian adults, providing evidence that the model theorized by Mayer, Salovey, and Caruso (2002) could be successfully used to assess Ability EI in the Italian community. Di Fabio and Saklofske (2014a, 2014b) performed two studies on EI in samples of Italian high school students. In the first study, they found that self-reported emotional intelligence added significant variance beyond the variance deriving from measures of intelligence and personality in predicting core self-evaluation, resilience and life satisfaction. In the second study, results confirmed the hypotheses that both self-reported Ability and Trait EI, assessed through the BarOn Emotional Intelligence Inventory and the Trait Emotional Intelligence Questionnaire, respectively, contributed more highly to career decision-making self-efficacy, career indecision and indecisiveness, than personality traits. Andrei, Smith, Surcinelli, Baldaro, and Saklofske (2016) investigated the factor structures and psychometric properties of the Italian version of the full-length Trait Emotional Intelligence Questionnaire. Results showed the association between EI scores and affect-related aspects of personality. Other research (Di Fabio, 2013; Di Fabio, Saklofske, \& Tremblay, 2016; Franco \& Tappatà, 2009) highlighted the relations between self-report measures of EI, self-other perception, and wellbeing, as observed in samples of individuals from the Italian community and college students. Similar findings were reported in subsequent research conducted on samples of Italian young adults and high school students (see Di Fabio, Kenny, \& Minor, 2014).

Despite the increasing corpus of research in the field of EI in the Italian context, to the best of our knowledge to date there is no Italian translation of the WLEIS available, and no studies have investigated the internal consistency of the scale in the Italian community. However, there are at least three major reasons to support the translation and validation of the WLEIS in the Italian context: (1) Although the comparability of psychological measures across different cultures represents a major challenge in psychological measurement, particularly in the field of emotions, the scale has been successfully translated and validated across several different cultural contexts, showing very good internal consistency and psychometric properties (Li et al., 2012), and some authors argued that research is needed to assess the internal consistency of the WLEIS in different contexts (Fukuda et al., 2012); (2) the Italian translation of the WLEIS will allow researchers in the field of EI to investigate the differences between the construct measured by the WLEIS and other important measures of EI that have been validated previously the Italian context, supporting a better understanding of the construct in Italian populations; (3) because previous research in the Italian context showed that both Ability and Trait EI measures are significant predictors of important psychological dimensions (Di Fabio \& Saklofske, 2014a, 2014b), the validation of the WLEIS will provide researchers in the field of EI in the Italian contexts with an internally consistent measure of EI, with significant implications for the improvement of assessment and intervention.

The present study was designed to translate the WLEIS in Italian language (WLEIS-I), to analyse its internal consistency and the factor structure in a sample of Italian adults from the community, and to investigate whether such measure of EI is consistent with the original model theorized by Wong and Law (2002). We also aimed at exploring the concurrent validity of the WLEIS by testing correlations between WLEIS scores and the Big Five factors of personality (measured by the ZuckermanKuhlman-Aluja Personality Questionnaire; Aluja, Kuhlman, \& Zuckerman, 2010), and self and other perception (measured by the 9 Attachment Profile; Candilera, 2007).

\section{Material and methods}

\subsection{Participants}

Participants were recruited from February 2016 to November 2016 at universities, public parks, shops, markets, banks, and post offices in three Italian regions that are highly representative of the demographic background of Italy: Piemonte (north), Lazio (mid), and Puglia (south). The sample included 476 subjects aged 18 to 58 ( $M=30.5$, $S D=9.2$ ), who voluntarily participated to the study. They were all 
Italian speakers, a prerequisite to understand the content and procedure of the tool well. Men were 61.3\% ( $n=292)$, and women 38.7\% ( $n=$ 184) of the sample. All participants were from lower to upper-middle class, having various educational and socio-economic backgrounds, and representing well enough the Italian population. They were, respectively for men and women, housewives (0-13.6\%), college students (22.6\%-12.0\%), unemployed (7.9\%-29.9\%), industry workers $(10.6 \%-$ $6.0 \%)$, employers $(38.0 \%-27.2 \%)$, retailers $(8.6 \%-4.3 \%)$, professionals (1.0\%-0.5\%), entrepreneurs (10.6\%-3.8\%), and teachers ( $0.7 \%-2.7 \%)$.

No differences were found between the age of men $(M=30.9 ; S D=$ 9.6) and women $(M=30.0 ; S D=8.4)\left(t_{(474)}=0.96 ; p=0.33\right)$, and no gender differences were found concerning years of education $\left(\chi_{(2)}^{2}=\right.$ $4.5 ; p=0.10)$. Years of education were, respectively for men and women: $\leq 8$ years $(2.4 \%-6.0 \%), \leq 13$ years $(42.8 \%-44.6 \%), \leq 18$ years (54.8\%-49.5\%). Moreover, no gender differences were found concerning the civil status $\left(\chi_{(1)}^{2}=0.66 ; p=0.79\right)$; they were, respectively for men and women, unmarried (64.6\%-63.4\%), married (35.4\%-36.6\%), and overall $6.9 \%$ of the participants did not report their civil status. All participants provided written informed consent to participate to the study.

\subsection{Procedure}

The English version of the WLEIS was translated into Italian by the authors of this paper, henceforth WLEIS-I, and then submitted to an English mother-tongue professional translator to assess independently the translation, by means of a back-translation. This process allowed agreement on the final Italian version of the instrument. The WLEIS-I is provided in the Appendix (Supplementary material). Participants of the study were administered the following set of measures to be completed in person: The WLEIS-I, the 9 Attachment Profile (9AP) and the Zuckerman-Kuhlman-Aluja Personality Questionnaire (ZKA-PQ). The $9 A P$ is an instrument that was developed and validated in the Italian context while for the ZKA-PQ we used the translation from the validation study in progress in the Italian context (De Pascalis, personal communication).

All analyses were carried out using SPSS 17.0 (SPSS Inc., Chicago, IL, USA). CFA was performed using AMOS 16.0 (AMOS: Analysis Of Moment Structures) (Arbuckle, 2007).

\subsection{Measures}

\subsubsection{Wong and Law Emotional Intelligence Scale (WLEIS; Wong E' Law, 2002)}

The WLEIS is a 16-item self-report rated on a 7-point Likert-type scale ( 1 = strongly disagree, $7=$ strongly agree), measuring four dimensions: (1) Self-Emotional Appraisal (SEA); (2) Others' Emotion Appraisal (OEA); (3) Use Of Emotion (UOE); (4) Regulation Of Emotions (ROE).

\subsubsection{Attachment Profile (9AP; Candilera, 2007)}

The 9AP is a semi-projective test for assessing the quality of the interpersonal relationships based on self/other perception and IWM of adult Attachment. Bowlby's notion of attachment representation involves ideas regarding both the self and the others, assuming that a person's representation of the self and the others can be characterized by either a positive or a negative orientation. The test includes seven basic pictures, with each picture showing black and white silhouettes in different scenarios. For each picture, two identical semantic differential 9-point scales are presented. Scales are lists of bipolar pairs of semantically opposite terms, and each scale includes nine items. For the first list, participants are asked to rate for each item their self-perception, and for the second list they are asked to rate their perception of the others. Higher scores for each item correspond to the first term of each bipolar scale (positive representation), lower scores correspond to the second term (negative representation). The two general indicators self-perception and other-perception, are the sum of the scores of the self-related and the other-related items, respectively. Higher scores in these two domains indicate good relationships with significant others, and a positive representation of self. We chose to employ this semi-projective measure since several studies have shown its reliability in assessing approximations of self/other perceptions (Iliceto et al., 2016; Iliceto et al., 2017). Moreover, because the 9AP provides a series of written responses for the figurative stimuli from the participants, it represents an objective semi-projective technique, with great advantage in comparison with purely objective techniques. In summary, we used the two general indicators of Self-perception ( $\alpha=0.86$ in this sample) and Other-perception ( $\alpha=0.83$ in this sample)

\subsubsection{Zuckerman-Kuhlman-Aluja Personality Questionnaire (ZKA-PQ;} Aluja et al., 2010).

The ZKA-PQ is a 200-item questionnaire based on the theoretical constructs of the alternative Five-factor model of personality. The instrument measures Aggressiveness (physical aggression, verbal aggression, anger, hostility), Activity (work compulsion, general activity, restlessness, work energy), Extraversion (positive emotions, social warmth, exhibitionism, sociability), Neuroticism (anxiety, depression, dependency, low self-esteem), and Sensation Seeking (thrill and adventure seeking, experience seeking, disinhibition, boredom susceptibility/ impulsivity). Higher scores in each sub-scale indicate a significant presence of each psychological construct. The authors reported that $\alpha$ for Aggressiveness, Activity, Extraversion, Neuroticism, and Sensation Seeking were $0.78-0.81,0.76-0.73,0.75-0.75,0.74-0.79$, and $0.70-$ 0.72 for the Spanish and American samples, respectively.

\subsection{Statistical analyses}

We used two-tailed $t$-tests and Pearson's correlations for continuous variables, and Chi-square tests with Yates' correction where appropriate for categorical variables. Internal consistency was analysed by means of Cronbach's $\alpha$. Confirmatory Factor Analysis (CFA) was used to test specific hypotheses concerning the relation between observed variables and their underlying latent constructs. CFA implies the formal specification of the measurement instrument in terms of a factor model, the statistical fitting of the factor model to the observed data (variances and covariances, or correlations), the assessment of fit, and the interpretation of whether the model is consistent with the data (Bollen, 1989).

We used the following criteria to evaluate the overall goodness of fit. The $\chi^{2}$ value close to zero indicates a small difference between expected vs. observed covariance matrices, with the probability level $>0.05$ evidencing the absence of meaningful unexplained variance (Jöreskog \& Sorbom, 1996). Because $\chi^{2}$ is sensitive to sample size, we also calculated the ratio of $\chi^{2}$ to degrees of freedom in order to better estimate the goodness of fit, with $<3$ as acceptable data-model fit (Kline, 2011). In addition, we utilized the Comparative Fit Index (CFI; Bentler, 1990), the Tucker-Lewis index (TLI; Tucker \& Lewis, 1973), the Root Mean Square Error of Approximation (RMSEA; Steiger, 1990) and the Standardized Root Mean Square Residual (SRMR; Jöreskog \& Sorbom, 1996). Indicators of a well-fitting model are evidenced by CFI and TLI $>0.95$, RMSEA < 0.06 and SRMR < 0.08 (Browne \& Cudeck, 1989; Hu \& Bentler, 1998, 1999).

\section{Results}

As a preliminary task, we calculated the Pearson's correlation coefficients between WLEIS-I subscales and the age of the participants. All values were below 1 and not statistically significant: SEA $(\mathrm{r}=$ $-0.085)$, OEA ( $r=-0.008)$, UOE $(r=-0.039)$, ROE ( $r=-0.038)$. Then we conducted a study in which we took gender into account. We compared men and women on all the sub-scales, but we did not find any statistically significant differences. The descriptive statistics and results of the comparisons are presented in Table 1. 
Table 1

Descriptive statistics and comparisons between men and women.

\begin{tabular}{|c|c|c|c|c|c|c|}
\hline \multirow[t]{2}{*}{ Measures } & \multicolumn{2}{|c|}{$\begin{array}{l}\text { Men }(n= \\
292)\end{array}$} & \multicolumn{2}{|c|}{$\begin{array}{l}\text { Women }(n= \\
184)\end{array}$} & \multirow[t]{2}{*}{$t_{(474)}$} & \multirow[t]{2}{*}{$p$} \\
\hline & $M$ & $S D$ & $M$ & $S D$ & & \\
\hline Self-Emotion Appraisal (WLEIS-I) & 4.96 & 1.02 & 5.06 & 0.96 & 1.01 & 0.30 \\
\hline $\begin{array}{l}\text { Other's Emotion Appraisal } \\
\text { (WLEIS-I) }\end{array}$ & 4.80 & 1.03 & 4.99 & 1.04 & 1.99 & 0.04 \\
\hline Use Of Emotion (WLEIS-I) & 4.52 & 1.11 & 4.5 & 1.01 & 0.18 & 0.85 \\
\hline Regulation Of Emotion (WLEIS-I) & 5.13 & 1.04 & 5.08 & 1.04 & 0.44 & 0.95 \\
\hline Self-perception (9AP) & 313.42 & 7.58 & 312.56 & 7.43 & 1.22 & 0.22 \\
\hline Other-perception (9AP) & 279.36 & 6.42 & 278.61 & 6.24 & 0.43 & 0.67 \\
\hline Aggressiveness (ZKA-PQ) & 102.00 & 11.30 & 101.98 & 10.92 & 0.02 & 0.98 \\
\hline Activity (ZKA-PQ) & 108.74 & 11.77 & 107.85 & 11.51 & 0.09 & 0.92 \\
\hline Extraversion (ZKA-PQ) & 120.44 & 15.36 & 119.67 & 15.17 & 0.15 & 0.87 \\
\hline Neuroticism (ZKA-PQ) & 91.90 & 19.32 & 92.27 & 19.52 & 0.12 & 0.89 \\
\hline Sensation seeking (ZKA-PQ) & 100.71 & 18.91 & 101.19 & 19.03 & 0.04 & 0.96 \\
\hline
\end{tabular}

The internal consistency of the sub-scale scores were assessed by means of Cronbach's $\alpha$; we found the following values for the subscales: SEA ( $\alpha=0.90)$, OEA ( $\alpha=0.89)$, UOE $(\alpha=0.91)$, ROE $(\alpha=$ 0.90 ); Cronbach's $\alpha$ for the WLEIS total score was 0.88 . The inter-correlations among the WLEIS subscales were moderate but all statistical significant (Table 2).

We used the covariance matrix and the maximum likelihood method to test the fit to the observed data of two CFA models. The first CFA model represented a four-factor model, and we used this model to test the hypothesis that the loadings of the observed variables, i.e. the 16 WLEIS-I item scores, were predicted to endorse onto the four factors of the original measuring instrument: SEA (items 1 to 4), OEA (items 5 to 8), UOE (items 9 to 12), and ROE (items 13 to 16). In this model, factors were allowed to inter-correlate, and all indicator cross-loadings were pre-specified to be equal to zero. This model produced fit indices as follows: $\left(\chi^{2}{ }_{(98)}=200.45 ; \mathrm{CFI}=0.981\right.$; RMSEA $\left.=0.047\right)$. Therefore, this four-factor model is appropriate to describe the relationships between the observed variables and the latent factors, and provides good fit with the data.

In order to test the construct validity of the measuring instrument, we hypothesized that WLEIS-I scores could be adequately represented by a hierarchical factorial structure, i.e. that the first-order four factors could be better explained by a single broader dimension of EI (Byrne, 2010). For this reason, we tested a single second-order factor with four first-order factors accounting for the covariation among the multiple factors. This model produced fit indices as follows: $\left(\chi_{(100)}^{2}=\right.$ 203.84; $\mathrm{CFI}=0.981 ;$ RMSEA $=0.046)$. All goodness-of-fit statistics of the models are summarized in Table 3.

Although the second-order solution did not improve significantly the goodness-of-fit, the appropriateness of the hierarchical structure of the model, with a single second-order factor and four first-order factors, was assessed in terms of magnitude of factor loadings. Following the recommendations of Brown (2006) to evaluate the acceptability of the model, we observed the magnitude of the second-order factor loadings: Each of the first-order factors strongly loaded onto the secondorder factor, as follows: SEA (0.60), OEA (0.53), UOE (0.52), ROE (0.51). We estimated the relationships of the WLEIS-I scores to the second-order factor by multiplying second-order factor loadings by their relevant first-order factor-loadings. Moreover, we employed the

Table 2

Intercorrelations.

\begin{tabular}{llll}
\hline & SEA & OEA & UOE \\
\hline Self-Emotion Appraisal (SEA) & - & & \\
Other's Emotion Appraisal (OEA) & $0.276^{* *}$ & - & \\
Use Of Emotion (UOE) & $0.303^{* *}$ & $0.302^{* *}$ & - \\
Regulation Of Emotion (WLEIS-I) & $0.288^{* *}$ & $0.160^{* *}$ & $0.270^{* *}$ \\
\hline$* * \quad p<0.001$ & & &
\end{tabular}

Table 3

Goodness-of-fit statistics.

\begin{tabular}{llllllll}
\hline Models & $\chi^{2}(\mathrm{df})$ & $\mathrm{p}$ & $\chi^{2} / \mathrm{df}$ & CFI & TLI & RMSEA & SRMR \\
\hline $\begin{array}{c}\text { 1) First-order } \\
\text { four-factor model }\end{array}$ & $200.45_{(98)}$ & $<0.001$ & 2.04 & 0.981 & 0.977 & 0.047 & 0.031 \\
2) Second-order & $203.84_{(100)}$ & $<0.001$ & 2.03 & 0.981 & 0.977 & 0.046 & 0.036 \\
\hline
\end{tabular}

transformation procedure introduced by Schmid and Leiman (1957). By following this procedure, we computed the factor loadings of the WLEIS-I scores onto the second-order factor, and the residualized factor loadings of the WLEIS-I scores onto the four first-order factors. The estimates of residualized first-order factors loadings represent the unique contribution of the first-order factors to the prediction of the observed variables, while maximizing the variance explained from the secondorder factor. As reported in Table 4, all the residualized first-order factor loadings were excellent $(>0.65)$, and each item presented salient loadings (all above about 0.40 ) onto the second-order factor representing a broader dimension of EI (Fig. 1).

Finally, we conducted a study to test the concurrent validity of the WLEIS-I, by means of exploratory correlations between the WLEIS-I scales and well-established measures of Self-Other perception (9AP) and personality (ZKA-PQ). As expected, we found positive and high correlations between SEA and Self-perception $(r=0.554 ; p<0.001)$, Other-perception $(r=0.487 ; p<0.001)$, and Extraversion $(r=0.491$; $p<0.001)$, and between OEA and Self-perception $(r=0.466 ; p<$ $0.001)$, Other-perception $(r=0.503 ; p<0.001)$, and Extraversion $(r$ $=0.457 ; p<0.001$ ). Moderate positive correlations were found between UOE and Self-perception $(r=0.305 ; p<0.001)$, and Extraversion $(r=0.332 ; p<0.001)$, and between ROE and Self-perception $(r=$ 0.389; $p<0.001)$, and Extraversion $(r=0.395 ; p<0.001)$ (Table 5).

\section{Discussion}

The objectives of the present study were to translate the WLEIS in Italian language, to test the internal consistency of the scale in a sample of Italian adults from the community, and to investigate whether the WLEIS-I is consistent with the original theoretical model theorized by Wong and Law (2002). The results showed that WLEIS-I is an internally consistent tool in assessing EI in the Italian population, with capacity to discriminate individuals in four dimensions, namely SEA, OEA, UOE, and ROE. The values of Cronbach's $\alpha$ computed on the four sub-scales and the overall questionnaire were above recommended values (Tabachnick \& Fidell, 2013), and they were comparable to those reported by Wong and Law (2002) in their original study. We investigated the

\section{Table 4}

Second-order factor loadings and residualized primary loadings.

\begin{tabular}{|c|c|c|c|c|c|}
\hline \multirow[t]{2}{*}{$\begin{array}{l}\text { WLEIS-I } \\
\text { items }\end{array}$} & \multirow[t]{2}{*}{$\begin{array}{l}\text { Emotional intelligence (second-order } \\
\text { factor loadings) }\end{array}$} & \multicolumn{4}{|c|}{$\begin{array}{l}\text { Residualized primary } \\
\text { loadings }\end{array}$} \\
\hline & & SEA & OEA & UOE & ROE \\
\hline Item-1 & 0.49 & 0.65 & & & \\
\hline Item-2 & 0.53 & 0.71 & & & \\
\hline Item-3 & 0.49 & 0.66 & & & \\
\hline Item-4 & 0.53 & 0.71 & & & \\
\hline Item-5 & 0.46 & & 0.73 & & \\
\hline Item-6 & 0.44 & & 0.70 & & \\
\hline Item-7 & 0.43 & & 0.70 & & \\
\hline Item-8 & 0.45 & & 0.71 & & \\
\hline Item-9 & 0.47 & & & 0.78 & \\
\hline Item-10 & 0.43 & & & 0.70 & \\
\hline Item-11 & 0.43 & & & 0.71 & \\
\hline Item-12 & 0.45 & & & 0.74 & \\
\hline Item-13 & 0.45 & & & & 0.76 \\
\hline Item-14 & 0.42 & & & & 0.71 \\
\hline Item-15 & 0.40 & & & & 0.67 \\
\hline Item-16 & 0.45 & & & & 0.77 \\
\hline
\end{tabular}




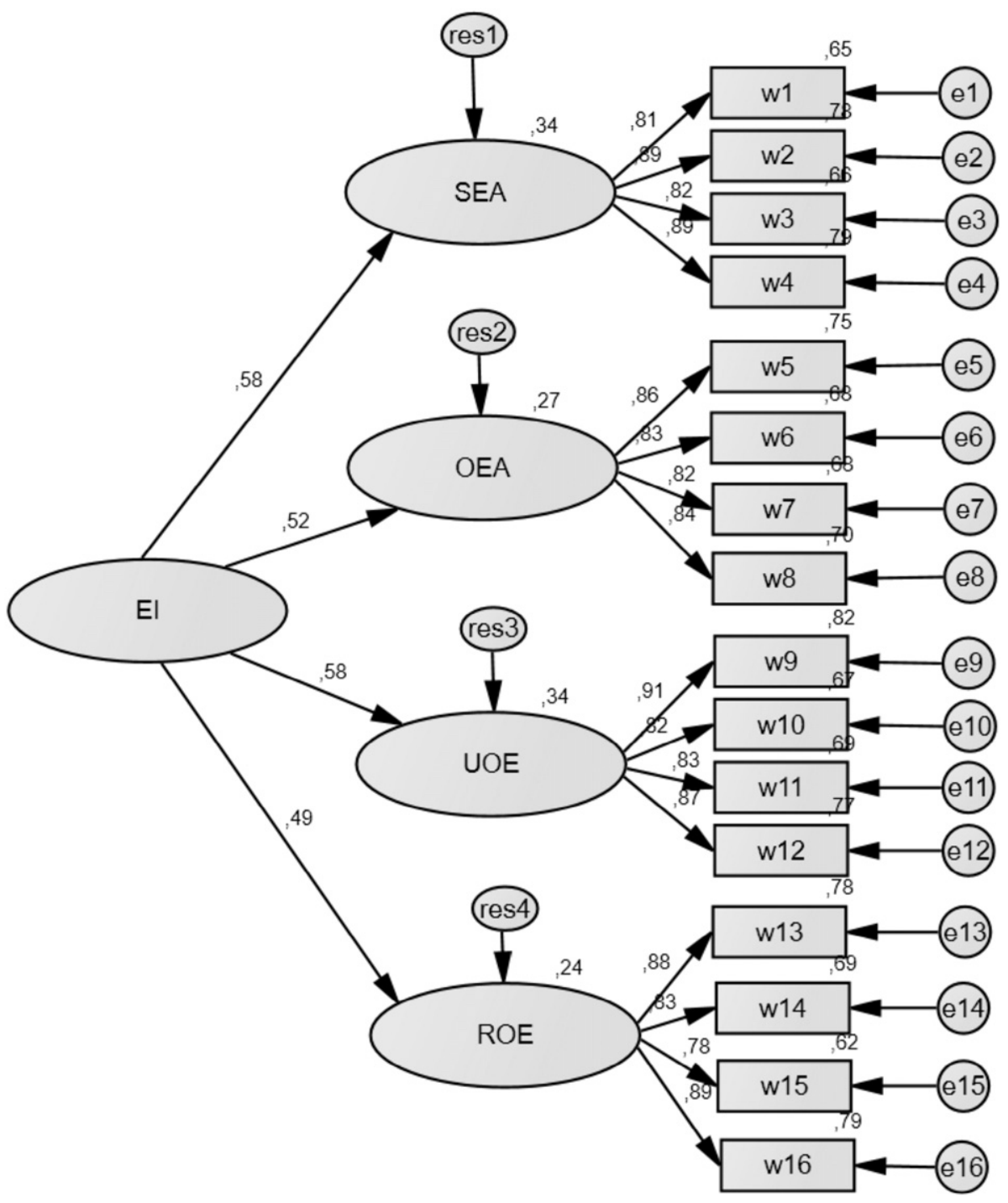

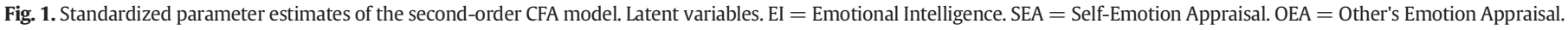
$\mathrm{UOE}=$ Use of Emotion. ROE = Regulation of Emotion. Observed variables. W1 to W16 = 16 items of the Wong and Law Emotional Intelligence Scale.

properties of original four-dimensional model and the fit with the data, and the model showed satisfactory fit indices, describing the relations between the observed variables and the underlying latent factors appropriately. Moreover, we found that the second-order factor model showed an appropriate hierarchical structure in terms of magnitude of factor loadings and model fit, with a single second-order factor loaded by four first-order factors. These results are consistent with the model theorized by Wong and Law (2002).

Table 5

Correlations matrix.

\begin{tabular}{lllll}
\hline & SEA & OEA & UOE & ROE \\
\hline Self-perception (9AP) & $0.554^{* *}$ & $0.466^{* *}$ & $0.305^{* *}$ & $0.389^{* *}$ \\
Other-perception (9AP) & $0.487^{* *}$ & $0.503^{* *}$ & 0.097 & $0.313^{* *}$ \\
Aggressiveness (ZKA-PQ) & 0.103 & 0.088 & 0.016 & 0.124 \\
Activity (ZKA-PQ) & 0.038 & 0.047 & 0.094 & 0.059 \\
Extraversion (ZKA-PQ) & $0.491^{* *}$ & $0.457^{* *}$ & $0.332^{* *}$ & $0.395^{* *}$ \\
Neuroticism (ZKA-PQ) & -0.148 & -0.127 & 0.036 & 0.078 \\
Sensation seeking (ZKA-PQ) & 0.071 & 0.028 & 0.076 & 0.110 \\
\hline
\end{tabular}

** $p<0.001$.
We also investigated the concurrent validity of the WLEIS-I, and we observed positive high correlations between SEA, Self-perception, Other-perception, and Extraversion, and between OEA, Self-perception, Other-perception, and Extraversion. We also found moderate positive correlations between UOE, Self-perception and Extraversion, and between ROE, Self-perception and Extraversion. These results are consistent with recent research (Brannick et al., 2009) showing that WLEIS scores are negatively correlated with neuroticism, and positively correlated with agreeableness and extraversion, and with empirical findings on the relations between EI and the Big Five factors of personality (Brackett and Mayer, 2003; Di Fabio \& Kenny, 2016; Freudenthaler, Neubauer, Gabler, Scherl, \& Rindermann, 2008; Mikolajczak, Petrides, Coumans, \& Luminet, 2009; Nelis, Quoidbach, Mikolajczak, \& Hansenne, 2009; Petrides \& Furnham, 2000, 2001). Moreover, these findings evidence the relations between EI and attachment styles, as discussed in previous research (Bonab \& Koohsar, 2011; Cherry et al., 2013; Gunning et al., 2011).

This study has limitations. Overall, the results obtained may be considered as preliminary, because of the relatively small sample size, requiring further consolidation by means of reliability and validity studies on larger representative samples. Test-retest reliability was 
not assessed, and regarding the validity of the tool, the measurement invariance across gender should be assessed. Moreover, the study does not provide evidence of convergent validity of the WLEIS-I, and research is required in this domain. In fact, to date scales assessing EI have been validated in the Italian context (see Di Fabio et al., 2014 for a review), but there is neither information available on the differences between the WLEIS-I and other reliable EI questionnaires in such context, nor regarding the relations between the convergent validity of the WLEIS-I in comparison to other instruments assessing Ability EI, Trait EI, and the Mixed EI, specifically (Di Fabio \& Kenny, 2016).

It has been argued that the observed overlap between trait and ability measures indicate incompatibility of the two models (Mayer, Roberts, \& Barsade, 2008), while other researchers consider the two models as complementary (Austin, Parker, Petrides, \& Saklofske, 2008; Mikolajczak, Nelis, Hansenne, \& Quoidbach, 2008; Parker, Keefer, \& Wood, 2011). However, no information is available about the relations between self-report measures of Trait EI, measures of Ability EI, and the model of EI proposed by Wong and Law (2002) specifically in the Italian context. Yet, the community sample utilized in the present study does not allow to generalize results to populations in which the assessment of $\mathrm{EI}$ is considered as critical for the adjustment and success of individuals, in both educational and organizational achievements ( $\mathrm{Di}$ Fabio \& Saklofske, 2014a, 2014b).

Future research is needed to test the reliability and psychometric properties of the WLEIS-I in Italian student and worker populations. Because participants were recruited from few specific geographic areas of the country, a more heterogeneous sample selection would also support a better understanding of the reliability of the instrument to the broader Italian community. Nevertheless, our findings regarding the concurrent validity of the WLEIS-I suggest the need to clarify the relations between the four dimensions of the WLEIS-I and personality dimensions, particularly between SEA, Self-perception, Other-perception, and Extraversion, and between OEA, Self-perception, Other-perception, and Extraversion. In fact, empirical findings suggest that the underlying model of the WLEIS might represent Ability EI rather than a trait (LaPalme et al., 2016), with potential implications for research and intervention. Future research should also investigate in depth the measurement model and the underlying construct of the WLEIS in relation to personality and attachment dimensions.

\subsection{Conclusions}

In conclusion, the present study provides evidence on the internal consistency of the WLEIS-I, confirming the original model posited by Wong and Law (2002). We consider it as a preliminary attempt to study the application of the WLEIS-I and its underlying model of EI to Italian community settings. Empirical evidence on the internal consistency and validity of the instrument will allow researchers, educators, and practitioners in the field of psychology to dispose of a reliable self-report measure for the assessment of EI and intervention in the community, with significant implications in terms of enhancement of individuals' subjective and psychological well-being.

Supplementary data to this article can be found online at http://dx doi.org/10.1016/j.paid.2017.05.006.

\section{Declaration of interest}

The authors report no conflicts of interest. The authors alone are responsible for the content and writing of the paper.

\section{Funding}

This research did not receive any specific grant from funding agencies in the public, commercial, or not-for-profit sectors.

\section{Acknowledgments}

This work was completed with the assistance of S\&P Statistics and Psychometrics Ltd, Rome, Italy.

\section{References}

Aluja, A., Kuhlman, M., \& Zuckerman, M. (2010). Development of the ZuckermanKuhlman-Aluja personality questionnaire (ZKA-PQ): A factor/facet version of the Zuckerman-Kuhlman personality questionnaire (ZKPQ). Journal of Personality Assessment, 92, 416-431. http://dx.doi.org/10.1080/00223891.2010.497406.

Andrei, F., Smith, M. M., Surcinelli, P., Baldaro, B., \& Saklofske, D. (2016). The trait emotional intelligence questionnaire: Internal structure, criterion and incremental validity in an Italian sample. Measurement and Evaluation in Counseling and Development, $49,34-45$.

Arbuckle, J. L. (2007). Amos 16 user's guide. Chicago, IL: SPSS

Austin, E., Saklofske, D. H., \& Egan, V. (2005). Personality, well-being and health correlates of trait emotional intelligence. Personality and Individual Differences, 38, 547-558. http://dx.doi.org/10.1016/j.paid.2004.05.009.

Austin, E. J., Parker, J. D., Petrides, K. V., \& Saklofske, D. H. (2008). Emotional intelligence. In G. J. Boyle, G. Matthews, \& D. H. Saklofske (Eds.), The SAGE handbook of personality theory and assessment. Vol. 1. (pp. 576-596). London: SAGE.

Barsade, S. G., Brief, A. P., \& Spataro, S. E. (2003). The affective revolution in organizational behavior: The emergence of a paradigm. In J. Greenberg (Ed.), Organizational behavior: The state of the science (pp. 3-52) (2nd ed.). Mahwah, NJ: Lawrence Erlbaum Associates Publishers.

Bentler, P. M. (1990). Comparative fit indexes in structural models. Psychological Bulletin, 107, 238-246. http://dx.doi.org/10.1037/0033-2909.107.2.238.

Bollen, K. A. (1989). Structural equations with latent variables. New York, NY: Wiley.

Bonab, B. G., \& Koohsar, A. A. H. (2011). Relation between emotional intelligence and attachment styles in delinquent adolescents. Procedia - Social and Behavioral Sciences, 30, 963-967. http://dx.doi.org/10.1016/j.sbspro.2011.10.187.

Brackett, M. A., \& Mayer, J. D. (2003). Convergent, discriminant, and incremental validity of competing measures of emotional intelligence. Personality and Social Psychology Bulletin, 29, 1147-1158. http://dx.doi.org/10.1177/0146167203254596.

Brannick, M. T., Wahi, M. M., Arce, M., Johnson, H. -A., Nazian, S., \& Goldin, S. B. (2009). Comparison of trait and ability measures of emotional intelligence in medical students. Medical Education, 43, 1062-1068. http://dx.doi.org/10.1111/j.1365-2923. 2009.03430.x

Brown, T. A. (2006). Confirmatory factor analysis for applied research. New York, NY: Guilford.

Browne, M. W., \& Cudeck, R. (1989). Single sample cross-validation indices for covariance structures. Multivariate Behavioral Research, 24, 445-455. http://dx.doi.org/10.1207/ s15327906mbr2404_4.

Byrne, B. M. (2010). Structural equation modeling with AMOS: Basic concepts, applications, and programming (2nd ed.). New York, NY: Routledge.

Candilera, G. (2007). 9 Attachment Profile (9AP). Manuale e norme. Roma: Scione Editore.

Carvalho, V. S., Guerrero, E., Chambel, M. J., \& González-Rico, P. (2016). Psychometric properties of WLEIS as a measure of emotional intelligence in the Portuguese and Spanish medical students. Evaluation and Program Planning, 58, 152-159. http://dx. doi.org/10.1016/j.evalprogplan.2016.06.006.

Cherry, M. G., Fletcher, I., \& O'Sullivan, H. (2013). Exploring the relationships among attachment, emotional intelligence and communication. Medical Education, 47. 317-325. http://dx.doi.org/10.1111/medu.12115.

Cooper, A., \& Petrides, K. V. (2010). A psychometric analysis of the trait emotional intelligence questionnaire-short form (TEIQue-SF) using item response theory. Journal of Personality Assessment, 92, 449-457. http://dx.doi.org/10.1080/00223891.2010. 497426.

D'Amico, A., \& Curci, A. (2010). Mayer-Salovey-Caruso emotional intelligence test (MSCEIT). Firenze: Giunti O.S.

Devonish, D., \& Greenidge, D. (2010). The effect of organizational justice on contextual performance, counterproductive work behaviors, and task performance: Investigating the moderating role of ability-based emotional intelligence. International Journal of Selection and Assessment, 18, 75-86. http://dx.doi.org/10.1111/j.1468-2389.2010. 00490.x.

Di Fabio, A. (2013). Trait emotional intelligence questionnaire (TEIQue): Un contributo alla validazione della versione italiana [Trait emotional intelligence questionnaire (TEIQue): A contribution to the validation of the Italian version]. Counseling. Giornale Italiano di Ricerca e Applicazioni. 6. (pp. 351-362).

Di Fabio, A., \& Kenny, M. E. (2016). Promoting well-being: The contribution of emotional intelligence. Frontiers in Psychology, 7. http://dx.doi.org/10.3389/fpsyg. 2016.01182

Di Fabio, A., Kenny, M. E., \& Minor, K. (2014). Emotional intelligence and positive psychology in the schools. In M. J. Furlong, R. Gilman, \& E. S. Huebner (Eds.), Handbook of positive psychology in the schools (pp. 450-464) (2nd ed.). New York, NY: Routledge, Taylor and Francis.

Di Fabio, A., \& Saklofske, D. H. (2014a). Comparing ability and self-report emotional intelligence, fluid intelligence, and personality traits in career decision. Personality and Individual Differences, 64, 174-178.

Di Fabio, A., \& Saklofske, D. H. (2014b). Promoting individual resources: The challenge of trait emotional intelligence. Personality and Individual Differences, 65, 19-23.

Di Fabio, A., Saklofske, D. H., \& Tremblay, P. F. (2016). Psychometric properties of the Italian trait emotional intelligence questionnaire (I-TEIQue). Personality and Individual Differences, 96, 198-201. http://dx.doi.org/10.1016/j.paid.2016.03.009. 
Franco, M., \& Tappatà, L. (2009). EQ-iTM Emotional Quotient Inventory. Validazione italiana [EQ-iTM Emotional Quotient Inventory. Italian validation]. Firenze: Giunti O. S.

Freudenthaler, H. H., Neubauer, A. C., Gabler, P., Scherl, W. G., \& Rindermann, H. (2008). Testing and validating the trait emotional intelligence questionnaire (TEIQue) in a German-speaking sample. Personality and Individual Differences, 45, 673-678. http:// dx.doi.org/10.1016/j.paid.2008.07.014.

Fukuda, E., Saklofske, D. H., Tamaoka, K., Fung, T. S., Miyaoka, Y., \& Kiyama, S. (2011). Factor structure of Japanese versions of Two Emotional Intelligence Scales. International Journal of Testing, 11, 71-92. http://dx.doi.org/10.1080/15305058.2010.516379.

Fukuda, E., Saklofske, D. H., Tamaoka, K., \& Lim, H. (2012). Factor structure of the Korean version of Wong and Law's Emotional Intelligence Scale. Assessment, 19, 3-7. http:// dx.doi.org/10.1177/1073191111428863.

Güleryüz, G., Güney, S., Aydin, E. M., \& Aşan, O. (2008). The mediating effect of job satisfaction between emotional intelligence and organisational commitment of nurses: A questionnaire survey. International Journal of Nursing Studies, 45, 1625-1635. http:// dx.doi.org/10.1016/j.ijnurstu.2008.02.004.

Gunning, M. D., Waugh, H., Robertson, F., \& Holmes, B. (2011). Emotional intelligence, attachment and bonding and communication. Community Practitioner, 84, 27-31.

Hu, L., \& Bentler, P. M. (1998). Fit indices in covariance structure modeling: Sensitivity to underparameterized model misspecification. Psychological Methods, 4, 424-453. http://dx.doi.org/10.1037//1082-989X.3.4.424.

Hu, L., \& Bentler, P. M. (1999). Cutoff criteria for fit indexes in covariance structure analysis: Conventional criteria versus new alternatives. Structural Equation Modeling: A Multidisciplinary Journal, 6, 1-55. http://dx.doi.org/10.1080/10705519909540118.

Iliceto, P., D'Antuono, L., Bowden-Jones, H., Giovani, E., Giacolini, T., Candilera, G., .. Panksepp, J. (2016). Brain emotion systems, personality, hopelessness, self/other perception, and gambling cognition: A structural equation model. Journal of Gambling Studies, 32, 157-169. http://dx.doi.org/10.1007/s10899-015-9543-0.

Iliceto, P., D'Antuono, L., Cassarà, L., Giacolini, T., Sabatello, U., \& Candilera, G. (2017). Obsessive-compulsive tendencies, self/other perception, personality, and suicidal ideation in a non-clinical sample. Psychiatric Quarterly, 88, 411-422. http://dx.doi.org/ 10.1007/s11126-016-9457-8.

Jöreskog, K. G., \& Sorbom, D. G. (1996). LISREL 8: User's reference guide. Chicago, IL: Scientific Software International.

Joseph, D. L., \& Newman, D. A. (2010). Discriminant validity of self-reported emotional intelligence: A multitrait-multisource study. Educational and Psychological Measurement, 70, 672-694. http://dx.doi.org/10.1177/0013164409355700.

Kafetsios, K., \& Zampetakis, L. A. (2008). Emotional intelligence and job satisfaction: Testing the mediatory role of positive and negative affect at work. Personality and Individual Differences, 44, 712-722. http://dx.doi.org/10.1016/j.paid.2007.10.004.

Kaushal, R., \& Kwantes, C. T. (2006). The role of culture and personality in choice of conflict management strategy. International Journal of Intercultural Relations, 30, 579-603. http://dx.doi.org/10.1016/j.jintrel.2006.01.001.

Kim, T. -Y., Cable, D. M., Kim, S. -P., \& Wang, J. (2009). Emotional competence and work performance: The mediating effect of proactivity and the moderating effect of job autonomy. Journal of Organizational Behavior, 30, 983-1000. http://dx.doi.org/10.1002/ job.610.

Kline, R. B. (2011). Principles and practice of structural equation modeling (3rd ed.). New York, NY: Guilford.

LaPalme, M. L., Wang, W., Joseph, D. L., Saklofske, D. H., \& Yan, G. (2016). Measurement equivalence of the Wong and Law Emotional Intelligence Scale across cultures: An item response theory approach. Personality and Individual Differences, 90, 190-198. http://dx.doi.org/10.1016/j.paid.2015.10.045.

Law, K. S., Wong, C. -S., \& Song, L. J. (2004). The construct and criterion validity of emotional intelligence and its potential utility for management studies. The Journal of Applied Psychology, 89, 483-496. http://dx.doi.org/10.1037/0021-9010.89.3.483.

Li, T., Saklofske, D. H., Bowden, S., Fung, T., \& Yan, G. (2012). The measurement invariance of the Wong and Law Emotional Intelligence Scale (WLEIS) across Three Chinese University Student Groups from Canada and China. Journal of Psychoeducational Assessment, 30, 439-452. http://dx.doi.org/10.1177/0734282912449449.

Libbrecht, N., De Beuckelaer, A., Lievens, F., \& Rockstuhl, T. (2014). Measurement invariance of the Wong and law emotional intelligence scale scores: Does the measurement structure hold across Far Eastern and European countries? Applied Psychology, 63, 223-237. http://dx.doi.org/10.1111/j.1464-0597.2012.00513.x.

Lindebaum, D., \& Cartwright, S. (2010). A critical examination of the relationship between emotional intelligence and transformational leadership. Journal of Management Studies, 47, 1317-1342. http://dx.doi.org/10.1111/j.1467-6486.2010.00933.x.
Mayer, J., \& Salovey, P. (1997). What is emotional intelligence? In P. Salovey, \& D. J. Sluyter (Eds.), Emotional development and emotional intelligence: Educational implications (pp. 3-34). New York: Basic Books.

Mayer, J. D., Salovey, P., \& Caruso, D. R. (2002). Mayer-Salovey- Caruso emotional intelligence test (MSCEIT): User's manual. Toronto, ON: Multi-Health Systems.

Mayer, J. D., Roberts, R. D., \& Barsade, S. G. (2008). Human abilities: Emotional intelligence. Annual Review of Psychology, 59, 507-536. http://dx.doi.org/10.1146/ annurev.psych.59.103006.093646.

Mikolajczak, M., Nelis, D., Hansenne, M., \& Quoidbach, J. (2008). If you can regulate sadness, you can probably regulate shame: Associations between trait emotional intelligence, emotion regulation and coping efficiency across discrete emotions. Personality and Individual Differences, 44, 1356-1368. http://dx.doi.org/10.1016/j.paid.2007.12. 004.

Mikolajczak, M., Petrides, K. V., Coumans, N., \& Luminet, O. (2009). The moderating effect of trait emotional intelligence on mood deterioration following laboratory-induced stress. International Journal of Clinical and Health Psychology, 9, 455-477.

Nelis, D., Quoidbach, J., Mikolajczak, M., \& Hansenne, M. (2009). Increasing emotional intelligence: (How) is it possible? Personality and Individual Differences, 47, 36-41. http://dx.doi.org/10.1016/j.paid.2009.01.046.

Parker, J. D., Keefer, K. V., \& Wood, L. M. (2011). Toward a brief multidimensional assessment of emotional intelligence: Psychometric properties of the emotional quotient inventory-Short form. Psychological Assessment, 23, 762-777. http://dx.doi.org/10. 1037/a0023289.

Pérez, J. C., Petrides, K. V., \& Furnham, A. (2005). Measuring trait emotional intelligence. In R. Schulze, \& R. D. Roberts (Eds.), Emotional intelligence: An international handbook (pp. 181-201). Ashland, OH: Hogrefe \& Huber Publishers.

Petrides, K. V. (2011). Ability and trait emotional intelligence. In T. Chamorro-Premuzic, S von Stumm, \& A. Furnham (Eds.), The Wiley-Blackwell handbook of individual differences (pp. 656-678). Chichester, UK: Wiley-Blackwell.

Petrides, K. V., \& Furnham, A. (2000). On the dimensional structure of emotional intelligence. Personality and Individual Differences, 29, 313-320. http://dx.doi.org/10.1016/ S0191-8869(99)00195-6.

Petrides, K. V., \& Furnham, A. (2001). Trait emotional intelligence: Psychometric investigation with reference to established trait taxonomies. European Journal of Personality, 15, 425-448. http://dx.doi.org/10.1002/per.416.

Petrides, K. V., Pita, R., \& Kokkinaki, F. (2007). The location of trait emotional intelligence in personality factor space. British Journal of Psychology, 98, 273-289. http://dx.doi. org/10.1348/000712606X120618.

Salami, S. O. (2009). Conflict resolution strategies and organisational citizenship behaviour: The moderating role of trait emotional intelligence. Europe's Journal of Psychology, 5, 41-63. http://dx.doi.org/10.5964/ejop.v5i2.266.

Salovey, P., \& Mayer, J. D. (1990). Emotional intelligence. Imagination, cognition and personality. Vol. 9. (pp. 185-211). http://dx.doi.org/10.2190/DUGG-P24E-52WK-6CDG.

Schmid, J., \& Leiman, J. M. (1957). The development of hierarchical factor solutions. Psychometrika, 22, 53-61. http://dx.doi.org/10.1007/BF02289209.

Steiger, J. H. (1990). Structural model evaluation and modification: An interval estimation approach. Multivariate Behavioral Research, 25, 173-180. http://dx.doi.org/10.1207/ s15327906mbr2502_4.

Tabachnick, B. G., \& Fidell, L. S. (2013). Using multivariate statistics (6th ed.). Boston, MA: Pearson/Allyn \& Bacon.

Tucker, L. R., \& Lewis, C. (1973). A reliability coefficient for maximum likelihood factor analysis. Psychometrika, 38, 1-10. http://dx.doi.org/10.1007/BF02291170.

Wang, Y. -S., \& Huang, T. C. (2009). The relationship of transformational leadership with group cohesiveness and emotional intelligence. Social Behavior and Personality, 37, 379-392. http://dx.doi.org/10.2224/sbp.2009.37.3.379.

Whitman, D. S., Van Rooy, D. L., Viswesvaran, C., \& Kraus, E. (2009). Testing the secondorder factor structure and measurement equivalence of the Wong and law emotional intelligence scale across gender and ethnicity. Educational and Psychological Measurement, 69, 1059-1074. http://dx.doi.org/10.1177/0013164409344498.

Wong, C. -S., \& Law, K. S. (2002). The effects of leader and follower emotional intelligence on performance and attitude: An exploratory study. The Leadership Quarterly, 13 243-274. http://dx.doi.org/10.1016/S1048-9843(02)00099-1.

Zysberg, L., \& Rubanov, A. (2010). Emotional intelligence and emotional eating patterns: A new insight into the antecedents of eating disorders? Journal of Nutrition Education and Behavior, 42, 345-348. http://dx.doi.org/10.1016/j.jneb.2009.08.009. 